\title{
5
}

\section{AS CRIITICAS DE AXEL HONNETH E NANCY FRASER À FILOSOFIA POLITICA DE JÜRGEN HABERMAS}

Jorge Adriano Lubenow*

RESUMO - O artigo apresenta os argumentos centrais da política deliberativa de Jürgen Habermas (1), e as perspectivas críticas de Axel Honneth (2) e Nancy Fraser (3) de forma a conferir à política habermasiana uma dimensão mais realista, um conteúdo político de vínculo mais concreto com a orientação emancipatória da práxis, e capaz de lidar melhor com a diferença, a diversidade e o conflito.

PALAVRAS-CHAVE - Axel Honneth. Jürgen Habermas. Nancy Fraser. Política. Reconhecimento.

ABSTRACT - The article presents the central arguments of Jürgen Habermas's deliberative politics (1), the critical standpoints offered by Axel Honneth (2) and Nancy Fraser (3) so as to provide Habermasian politics with a more realistic dimension, a political content with a more concrete orientation of emancipatory praxis, and enable it to cope with difference, diversity, and conflict.

KEYWORDS - Axel Honneth. Jürgen Habermas. Nancy Fraser. Politics. Recognition.

\section{A política deliberativa de Habermas}

Na obra Faktizität und Geltung (1992), ${ }^{1}$ Habermas elabora um amplo conceito de política deliberativa, ancorado num modelo de circulação de poder denominado de "eclusas", e com ênfase na institucionalização. Neste modelo, os processos de comunicação e decisão do sistema político estão ancorados no mundo da vida por uma abertura estrutural, permitida por uma esfera pública sensível, porosa, capaz de introduzir no sistema político os conflitos existentes na periferia.

A concepção de política deliberativa é uma tentativa de formular uma teoria da democracia a partir de duas tradições teórico-políticas: a

* Doutor em Filosofia pela UNICAMP. Professor Adjunto I da UFPI. Professor Permanente junto ao Mestrado em Ética e Epistemologia da UFPI e Pesquisador DCR/ CNPq 1C (2007-2010).E-mail: lubenow@ufpi.edu.br

1 Jürgen Habermas, Faktizität und Geltung. Frankfurt: Suhrkamp, 1992, 2v.

\begin{tabular}{|l|l|l|l|l|l|}
\hline Veritas & Porto Alegre & v. 55 & n. 1 & jan./abr. 2010 & p. 121-134 \\
\hline
\end{tabular}


concepção de autonomia pública da teoria política republicana (vontade geral, soberania popular), com a concepção de autonomia privada da teoria liberal (liberdades individuais, interesses particulares). Ela pode ser concebida, simultaneamente, como um meio-termo e uma alternativa aos modelos republicano e liberal. ${ }^{2}$

Para Habermas, dois modelos normativos de democracia dominaram o debate até aqui: o liberal e o republicano. Diante destes, propõe um modelo alternativo, o procedimental-deliberativo. ${ }^{3}$ A dimensão política comparativa tomada pelo autor é a formação democrática da opinião e da vontade; ${ }^{4}$ além disso, o entendimento distinto do processo democrático carrega também compreensões normativas distintas de estado e sociedade, e para a compreensão da legitimidade e da soberania popular.

O modelo deliberativo acolhe elementos dos modelos liberal e republicano e os integra de uma maneira nova e distinta num conceito de procedimento ideal para deliberações e tomadas de decisão. Esta compreensão do processo democrático tem conotações normativas mais fortes que o modelo liberal, mas menos normativas do que o modelo republicano. Como o republicanismo, a teoria discursiva da democracia reserva uma posição central ao processo político de formação da opinião e da vontade, entretanto sem entender como algo secundário a constituição jurídico-estatal. ${ }^{5}$ Como o modelo liberal, também na teoria discursiva da democracia os limites entre Estado e sociedade são respeitados. Todavia, aqui, a sociedade civil, como base social das opiniões públicas autônomas, distingue-se tanto dos sistemas de ação econômicos quanto da administração pública. Dessa compreensão do procedimento democrático resulta normativamente a exigência de um deslocamento dos pesos que se aplicam a cada um dos elementos na relação entre os três recursos, a saber, dinheiro, poder administrativo e solidariedade, a partir das quais as sociedades modernas preenchem sua necessidade de integração e de regulação. As implicações normativas são evidentes: a força sociointegrativa da solidariedade, que não pode mais ser obtida, mas ser extraída apenas das fontes da ação comunicativa, precisa desenvolver-se em espaços públicos autônomos diversos e procedimentos de formação democrática da opinião e da vontade política institucionalizados jurídico-

2 Jessé Souza. "A singularidade Ocidental como aprendizado reflexivo: Jürgen Habermas e o conceito de esfera pública", in Ed. UnB, 2000, p. 59.

3 Jürgen Habermas, "Drei normative Modelle der Demokratie", in des Anderen. Suhrkamp, 2006, p. 277.

4 Habermas, "Drei normative Modelle der Demokratie", p. 285.

5 Habermas, "Drei normative Modelle der Demokratie", p. 287. 
estatalmente; e ser capaz de se afirmar contra os outros dois poderes, dinheiro (mercado) e poder administrativo (estado). ${ }^{6}$

"Deliberação" é uma categoria normativa que sublinha uma concepção procedimental de legitimidade democrática. Esta concepção normativa gera uma matriz conceitual diferente para definir a natureza do processo democrático, ${ }^{7}$ sob os aspectos regulativos (exigências normativas) da publicidade, racionalidade e igualdade. ${ }^{8} \mathrm{O}$ princípio procedimental da democracia visa amarrar um procedimento de normatização (o que significa: um processo de institucionalização da formação racional da opinião e da vontade), através do caráter procedimental, que garante formalmente igual participação em processos de formação discursiva da opinião e da vontade e estabelece, com isso, um procedimento legítimo de normatização. Nesse caminho via procedimento e deliberação, que constitui o cerne do processo democrático, pressupostos comunicativos de formação da opinião e da vontade funcionam como a "eclusa" mais importante para a racionalização discursiva das decisões no âmbito institucional. Procedimentos democráticos proporcionam resultados racionais na medida em que a formação da opinião e da vontade institucionalizada é sensível aos resultados de sua formação informal da opinião que resulta das esferas públicas autônomas e que se formam ao seu redor. As comunicações públicas, oriundas das redes periféricas, são captadas e filtradas por associações, partidos e meios de comunicação, e canalizadas para os foros institucionais de resolução e tomadas de decisão:

A chave da concepção procedimental de democracia consiste precisamente no fato de que o processo democrático institucionaliza discursos e negociações com o auxílio de formas de comunicação as quais devem fundamentar a suposição de racionalidade para todos os resultados obtidos conforme o processo. ${ }^{9}$

A concepção deliberativa da democracia considera a participação dos cidadãos nas deliberações e nas tomadas de decisão o elemento central da compreensão do processo democrático. Nesse sentido, focaliza os elementos formais e normativos, como a exigência do aumento da participação dos cidadãos nos processos de deliberação e decisão e o fomento de uma cultura política democrática. O procedimento da deliberação não é apenas uma etapa de discussão que antecede a tomada de decisão. Mais do que isso, ela tem o objetivo de justificar as decisões

6 Habermas, "Drei normative Modelle der Demokratie", p. 288-289.

7 Habermas, "Drei normative Modelle der Demokratie", p. 277.

8 Habermas, "Political communication in media society", p. 4. (manuscrito, 2006)

9 Habermas, Faktizität und Geltung, p. 368. 
a partir de razões que todos poderiam aceitar. Esse é o procedimento deliberativo da razão pública: fornecer um espectro de razões que poderiam ser aceitas por todos os possíveis atingidos, ainda que nem todos compartilhem com o tema ou assunto em questão, ou com a mesma filosofia de vida. Segundo Marcos Nobre:

O procedimento, para Habermas, é "formal", mas não em oposição a conteúdos determinados, de que ele seria a abstração, ou em relação aos quais ele seria "vazio", mas o processo capaz de permitir o surgimento do maior número possível de vozes, de alternativas de ação e de formas de vida, garantindo seu direito de expressão e de participação. Ele é formal também no sentido de que o processo de deliberação política não pode ser orientado por nenhuma forma de vida determinada, por nenhum modelo concreto do que deva ser a sociedade ou os cidadãos que vivem em um Estado Democrático de Direito. ${ }^{10}$

Como podemos ver, a deliberação é um procedimento que indica "quem" deve participar e "como", mas não tem nada a dizer sobre o preenchimento dos "conteúdos" normativos, sobre "o que" deve ser decidido. Ou seja, as regras do jogo democrático - eleições regulares, princípio da maioria, sufrágio universal, alternância de poder - não fornecem nenhuma orientação nem podem garantir o "conteúdo" das deliberações e decisões. Os "pressupostos idealizadores" - de inclusão, acesso universal, direitos comunicativos iguais, participação sob igualdade de direitos, igualdade de chances para todas as contribuições, ausência de coações - apenas têm o caráter de garantir formalmente uma pressuposição fática para gozar chances iguais. ${ }^{11}$ Por esse modo, o princípio formal da deliberação democrática não pode ser confundido ou reduzido a outros bens, também valiosos, como "justiça social", "Estado de direito", "direitos sociais" e "direitos culturais", mais próximos das teorias explicativas da democracia, fundados nos interesses e nas preferências dos indivíduos (preferências e interesses substantivos: ou sociais, ou materiais, ou culturais, ou ainda outros). Os procedimentos deliberativos escapam das restrições de uma única dimensão da razão prática, seja moral, ética ou pragmática. ${ }^{12}$ Nesse sentido, os aspectos procedimentais do uso público da razão, ao confiarem mais no procedimento deliberativo de uma formação da opinião e da vontade, podem deixar questões em aberto. ${ }^{13}$

10 Marcos Nobre, "Introdução", in: Marcos Nobre \& Ricardo Terra. Direito e democracia: um guia de leitura. Malheiros, 2007, p. 18.

11 Habermas, "Anhang zu 'Faktizität und Geltung'”, in: Die Einbeziehung des Anderen, p. 340-341.

12 Denílson Werle, "Democracia deliberativa e os limites da razão pública", in: Marcos Nobre \& Vera Coelho. Participação e deliberação. Editora 34, 2004, p. 148-149.

13 Segundo Habermas, "não é possível estabilizar definitivamente expectativas de comportamentos sociais, que dependem de soluções falíveis e precárias", in: Faktizität und Geltung, v. I, p. 57. 
Esta compreensão falível do paradigma procedimental tem implicações sobre a compreensão da justiça e o sentido da igualdade. A compreensão procedimental habermasiana visa explicitar, em forma de crítica, as debilidades normativas dos modelos liberal e republicano, que, por exemplo, fixam de antemão a escolha sobre o sentido da igualdade jurídica; ou fixam de antemão quais assuntos são privados e quais são públicos. Com o paradigma procedimental, a determinação do sentido da igualdade é lançado no campo político de comunicação pública. O conteúdo da igualdade jurídica deve ser considerado objeto de uma disputa política. Um conflito no qual o sentido da igualdade é decidido num processo de comunicação pública, conduzido pelos próprios participantes e possíveis afetados por meio do exercício público de formação democrática da opinião e da vontade. O modelo deliberativo considera os próprios concernidos como responsáveis pela definição dos critérios de igualdade a serem aplicadas ao sistema de direitos.

Com isso, a fundamentação de igualdades materiais é incorporada na teoria democrática como uma disputa política em torno do que precisa ser reconhecido. Uma luta pelo reconhecimento jurídico de necessidades e exigências normativas peculiares em relação ao conjunto de toda a comunidade jurídica, na qual os grupos interessados procuram apresentar aos demais as experiências particulares de exclusão social, discriminação e carências em vista do convencimento sobre a necessidade de um tratamento jurídico formalmente diferenciado. Segundo o princípio amplo da igualdade do conteúdo do direito, aquilo que é igual sob aspectos relevantes deve ser tratado de modo igual, e aquilo que é diferente deve ser tratado de modo diferente. ${ }^{14}$

Esta perspectiva procedimental abre a possibilidade de avaliação motivada pela própria experiência sofrida com a não realização de direitos, das alternativas existentes em relação à permanência no paradigma social ou um retorno ao paradigma liberal. Nesse sentido, Habermas encontra a emergência do paradigma procedimental já enraizada em algumas vertentes da prática jurídica contemporânea, que se vê encurralada entre a crítica ao modelo social e a rejeição do retorno ao modelo liberal. No entanto, é em certos desenvolvimentos de movimentos feministas de esquerda norte-americanos que Habermas encontra a melhor expressão das exigências normativas, da necessidade de uma orientação procedimentalista da prática jurídica contemporânea: o movimento feminista, ao ter experimentado as limitações específicas de ambos os paradigmas anteriores, estaria agora em condições de negar a cegueira em relação às desigualdades factuais do modelo paternalista

${ }_{14}$ Habermas, Faktizität und Geltung, p. 494-99. 
social. Nesse caso, as diferentes interpretações sobre a identidade dos sexos e suas relações mútuas têm de se submeter a discussões públicas constantes, no qual as próprias concernidas podem reformular o tema ou assunto em questão a ser reconhecido, e elas mesmas decidirem quais as necessidades que precisam ser corrigidas pelo medium do direito. ${ }^{15}$

Os argumentos em favor da concepção deliberativa de esfera pública e de política têm sido alvo de muitas críticas. Muitos teóricos que se ocupam com teorias democráticas têm questionado as assunções básicas da teoria política deliberativa que resulta da obra sobre direito e democracia, apontando vários pontos frágeis: o seu incansável procedimentalismo; o caráter idealista; de que a proposta de uma reforma democrática das instituições não seria tão radical assim; a incapacidade de fornecer princípios substantivos de justiça social; de que, apesar da intencionalidade prática, Habermas não explicita nenhum destinatário em particular; que as características ou pressupostos deliberativos se manifestam apenas em formas específicas e restritas. A ênfase da deliberação é nos elementos normativos e consensuais do modelo deliberativo ou é uma ênfase realista os interesses e no potencial de conflito neles contido? O modelo deliberativo consegue neutralizar e suspender disparidades econômicas, sociais, culturais, cognitivas, entre outras, e promover um resultado satisfatório, de igualdade e justiça? Seu aspecto cognitivo realmente introduz uma gradual abolição destas desigualdades e disparidades, promove igualdade e produz resultados políticos justos? Enfim, trata-se de processos de deliberação ideal ou de deliberação efetiva?

Não podemos acompanhar em sua amplitude a bibliografia crítica sobre política deliberativa ${ }^{16}$. Para nossos propósitos, vamos aqui nos

15 Habermas, Faktizität und Geltung, p. 504-15. Sobre o debate feminista, ver: Young. Justice and the politics of difference. Princeton Univ. Press, 1990; Young. Inclusion and democracy. Oxford Univ. Press, 2000; Fraser. Justice interruptus. Routledge, 1997; Benhabib. Democracy and difference. Princeton Univ. Press, 1996; Benhabib. The claims of culture. Princeton Univ. Press, 2002; Landes. "Jürgen Habermas, the structural transformation of the public sphere: a feminist inquiry", in: Praxis International, 12 (1992), p. 106-127.

16 Sobre as vantagens e desvantagens da deliberação, ver: W. Scheuerman, "Between radicalism and resignation: democratic theory in Habermas's 'Between Facts and Norms'", in: Dews, Habermas: a critical reader, 1999, p. 153; A. Bächtiger et al., "Empirical Approaches to Deliberative Democracy", in: Acta Politica 40, n. 2-3, 2005; J. Fishkin. Democracy and deliberation. Yale, 1995; Gutmann \& Thompson. Democracy and disagreement. Harward Univ. Press, 1994; Bohman \& Regh. Deliberative democracy. MIT Press, 1997; J. Elster. Deliberative democracy. Cambridge Univ. Press, 1998; Rosenfeld \& Arato. Habermas on law and democracy. Univ. of California Press, 1998; J. Dryzek. Deliberative democracy and beyond. Oxford Univ. Press, 2000; Fishkin \& Laslett. Debating deliberative democracy. GB Verlag, 2002; J. Parkinson. Deliberating in the real world: problems of legitimacy in deliberative 
limitar apenas os comentários críticos sobre a política habermasiana de Axel Honneth e Nancy Fraser, ${ }^{17}$ por manterem uma relação estreita com o campo teórico da Teoria Crítica.

\section{A política do reconhecimento de Honneth}

Axel Honneth, que sucedeu Habermas em seu posto na Universidade de Frankfurt a partir de 1996, desenvolve uma variante política significativamente diferente de Habermas, focada, não no entendimento e no consenso, mas nas dimensões psicológicas e pessoais da dominação e da emancipação; não numa concepção procedimental de política e de lei, mas numa concepção formal da vida ética, cujo conceito central é do "reconhecimento". ${ }^{18}$

O cerne da crítica de Honneth é a compreensão habermasiana de sociedade em dois níveis: sistema e mundo da vida (que nada mais seria que um alargamento do conceito de racionalidade e de ação social, acrescentando à dimensão sitêmica uma outra, o mundo da vida), dois pólos opostos e nada a mediar entre eles. Este seria o "déficit sociológico"

democracy, Oxford Univ. Press, 2006; S. Macedo. Deliberative politics: essays on democracy and disagreement. Oxford Univ. Press, 1999; B. Lösch. Deliberative Politik. Moderne Konzeptionen von Öffentlichkeit, Demokratie und politischer Partizipation. Westfälisches Dampfboot, 2005; R. Talisse. Democracy after liberalism: pragmatism and deliberative politics. New York Univ. Press, 2005; Nobre \& Coelho. Participação e deliberação. Ed. 34, 2004; Werle \& Melo. Democracia deliberativa. Singular, 2007; Lubenow. "A categoria de esfera pública em Jürgen Habermas: para uma reconstrução da autocrítica", in: Cadernos de Ética e Filosofia Política (USP), 10, 1 (2007), p. 103-123.

17 Axel Honneth. Kritik der Macht. Suhrkamp, 1985; Honneth. Kampf um Anerkennung. Suhrkamp, 1992; Honneth. Pathologien der Vernunft: Gesichte und Gegenwart der Kritische Theorie. Suhrkamp, 2007; Honneth, "The social dynamics of disrespect: situating critical theory today", in: P. Dews. Habermas: a critical reader. Blackwell, 1999, p. 320-337; Honneth, "The other of justice: Habermas and the ethical challenge of postmodernism", in: S. White. The Cambridge companion to Habermas. Cambridge Univ. Press, 1995, p. 289-323; Fraser \& Honneth. Umverteilung oder Anerkennung? Eine politisch-philosophische Kontroverse. Suhrkamp, 2003; Fraser, "Rethinking Recognition", in: New Left Review 3, 2000, p. 107-20; Fraser. "Rethinking the public sphere: a contribution to the critique of the actually existing democracy", in: Calhoun. Habermas and the public sphere. MIT Press, 1992, p. 109-42. Além disso, ver: Chambers, "The Politics of Critical Theory", in: F. Rush. The Cambridge Companion to Critical Theory, 2004, p. 219-47; Hanks. Refiguring critical theory: Jürgen Habermas and the possibilities of political change. Univ. Press of America, 2002; Freundlieb. Critical Theory after Habermas: encounters and departures. Brill Verlag, 2004; Marsh, "What's critical about critical theory?", in: Hahn. Perspectives on Habermas. Open Court, 2000; Nobre, "Luta por reconhecimento: Axel Honneth e a Teoria Crítica", in: Honneth. Luta por reconhecimento. Ed. 34, 2003, p. 7-19; Nobre. A teoria crítica. Zahar, 2004.

${ }^{18}$ Honneth. Kampf um Anerkennung. Suhrkamp, 1992. 
da teoria crítica da sociedade de Habermas. ${ }^{19}$ Em outras palavras: haveria uma "insuficiência sociológica" na teoria habermasiana, apesar do grande peso da Sociologia em sua primeira obra (Strukturwandel der Öffentlichkeit, 1962), algo que também não teria sido corrigido nas duas obras posteriores mais representativas do arcabouço teórico habermasiano: Theorie des kommunikativen Handelns (1981) e Faktizität und Geltung (1992). ${ }^{20}$ Por isso a sugestão honnethiana da "ação social" como mediador necessário. A distinção habermasiana entre sistema e mundo da vida seria mais analitica que empírico-descritiva, e o domínio social da ação comunicativa tornaria incapaz de pensar o próprio sistema e sua lógica instrumental como resultado de permanentes conflitos, capazes de moldá-lo conforme as correlações de forças sociais e políticas. Ou seja, para Honneth, Habermas se esquivou da base da interação social, que não é o entendimento e o consenso, mas o conflito, e sua gramática a luta por reconhecimento. Habermas seria por demais abstrata e menânica, ignorando largamente o fundamento da ação social, que é o conflito social. Por isso, Honneth vai partir dos conflitos sociais para construir uma teoria com implicações mais práticas, empíricas. Por isso lhe interessam aqueles conflitos que se originam de uma experiência de desrespeito social, de um ataque a identidade pessoal ou coletiva, capaz de suscitar uma ação que busque restaurar relações de reconhecimento mútuo ou desenvolvê-las num nível evolutivo superior. As dimensões experienciais tomadas por Honneth - e que também servem como critérios normativos - são a esfera emotiva, a jurídico-moral e a da estima social. ${ }^{21}$

Dados estes argumentos, é preciso perguntar: a crítica de Honneth a Habermas é basicamente uma crítica política? A interpretação honethiana

19 A crítica de Honneth à distinção habermasiana entre sistema e mundo da vida é desenvolvida na obra Kritik der Macht. Suhrkamp, 1985.

20 Apesar do pano de fundo sociológico em sua primeira obra (Strukturwandel der Öffentlichkeit, 1962), a partir da década de 70 Habermas busca remover a crítica social arraigada nas condições historiográficas para as características universais da ação comunicativa intersubjetiva (cf. Theorie des kommunikativen Handelns, 1981). Esta reorientação é uma estratégia para ampliar a capacidade explicativa de sua teoria e dar conta das novas dinâmicas e fenômenos que surgem e que desafiam a compreensão do vínculo teoria-práxis. Nesse sentido, é importante a reformulação da categoria de esfera pública, o resgate da importância da sociedade civil e a sua ênfase institucional no quadro da teoria deliberativa da democracia nos anos 90 (cf. Faktizität und Geltung, 1992). Mas, apesar disso, - e essa é a crítica de Honneth e Fraser - as implicações práticas para uma extensão da categoria deliberativa de política se tornaram problemáticas nas sociedades funcionalmente complexas e culturalmente pluralistas, e exigem uma análise mais realista, um vínculo mais concreto com uma orientação emancipatória da práxis.

21 Honneth. Kampf um Anerkennung, especialmente cap. 2 e 3. Ver também: Nobre, "Luta por reconhecimento: Axel Honneth e a Teoria Crítica", p. 13-18; Werle \& Melo, "Reconhecimento e justiça na teoria crítica da sociedade em Axel Honneth", in: Nobre. Curso livre de Teoria Crítica, Papirus, 2008, p. 183-198. 
de Habermas toma como ponto de partida a postura política habermasiana? Enfim, qual é o cerne da política de Honneth? E qual é o cerne da crítica de Honneth à política de Habermas? Parece-me que ela indireta. A crítica é à teoria da sociedade (argumento direito) e, por consequência, à teoria política (argumento indireto). Ou seja, a crítica de Honneth à Habermas dáse pela via da teoria social (e não pela via da política). ${ }^{22}$ Essa é a tese.

Por conseguinte, é preciso saber se a noção de "luta por reconhecimento" realmente consegue preencher o déficit sociológico diagnosticado em Habermas? E de que modo as reivindicações por reconhecimento são justificados (incorporados) no plano político?

Para Chambers, apesar da perspectiva de Honneth querer ser "mais prática", "historicamente situada", embora busque caracterizar a injustiça e o conflito de modo mais concreto (do que Habermas), as implicações políticas da teoria do reconhecimento não são mais claras - no sentido de dizer "o que deve ser feito?" - e, nesse sentido, Honneth não seria "mais político" que Habermas. ${ }^{23}$

Essa crítica à "insuficiência política" da teoria do reconhecimento de Honneth também é colocada em questão por outros autores. Para Werle e Melo, talvez a teoria crítica de Honneth esteja cometendo um "déficit político", pois não há a explicitação fundamental de um princípio de justificação pública, em que os próprios cidadãos possam decidir quais formas de reconhecimento e princípios de justiça são legítimos ou ilegítimos. Em contrapartida, tal problema - dos critérios normativos

22 Essa hipótese é corroborada pela ordem cronológica das publicações envolvidas. É preciso notar que o argumento de Honneth sobre o déficit sociológico de Habermas aparece na obra sobre a crítica do poder (de 1985), e sua contraproposta aparece na obra sobre o reconhecimento, de 1992. O problema - e isso reforça a hipótese de que Honneth tem um déficit de argumentos políticos habermasianos - é que estas duas obras, centrais na crítica à Habermas, não tomam como ponto de partida a postura política madura de Habermas formulada e publicada na obra sobre direito e democracia, em 1992. É curioso que em nenhuma das obras posteriores a luta por reconhecimento Honneth busca sanar essa deficiência e incorporar os argumentos e questões da obra política de Habermas (Faktizität und Geltung, 1992): nem em Leiden an Unbestimmtheit (2001), que é uma reatualização da filosofia do direito de Hegel com o propósito de fundamentar uma teoria da justiça vinculada à perspectiva da Teoria Crítica, capaz de fornecer um diagnóstico do tempo, do "sofrimento de indeterminação" como uma patologia que resulta da realização incompleta ou insuficiente da vontade livre em âmbitos institucionais da sociedade moderna não estruturados conforme a eticidade; nem em Verdinglichung (2005), que redefine, da perspectiva de uma teoria do reconhecimento, a "reificação" como conceito-chave da filosofia crítica; nem em Pathologien der Vernunft (2007), que trata da história e atualidade da teoria crítica; nem em Disrespect: the normative foudations of critical theory (2007), que explora os limites de uma teoria procedimental da justiça, as relações sociais e as condições políticas de sua realização.

23 Chambers, "The politics of Critical Theory", in: Rush. The Cambridge Companion to Critical Theory, 2004, p. 238. 
próprios de um contexto político que seriam capazes de avaliar as lutas por reconhecimento nesse campo - talvez pudesse ser sanado se Honneth propusesse uma outra esfera de reconhecimento, junto com as outras - amor, direito e solidariedade - "uma forma propriamente política de reconhecimento intersubjetivo", que estivesse em consonância com a concepção liberal igualitária da cidadania democrática:

(...) a proposta de Honneth de uma Teoria Crítica fundamentada nas relações intersubjetivas de reconhecimento e de luta por reconhecimento, se, por um lado, consegue fornecer meios para sanar o déficit sociológico da Teoria Crítica em geral, e das teorias da justiça em particular, por outro, deixa em aberto uma questão que não é menos fundamental: a política. (...) a política não tem um estatuto específico na obra de Honneth. Não se coloca no horizonte de suas preocupações a questão do critério normativo fundamental que poderia regular a formação imparcial de acordos políticos para as lutas por reconhecimento. ${ }^{24}$

Para Saavedra e Sobottka, faz-se necessário, hoje, o pensamento crítico das instituições do estado democrático de direito: "Como é possível combinar a idéia hegeliana de luta por reconhecimento com as instituições de um estado democrático de direito?", e também "como é possível pensar instituições a partir do conceito de reconhecimento, dado que Honneth, desde o início, e ainda hoje, pretende desenvolver esse conceito sem se fazer valer, como Habermas, da teoria dos sistemas?"25 Trata-se, de certa maneira, de uma questão que não diz respeito apenas a teoria de Honneth, mas ao estatuto atual da teoria crítica mesma, da sua capacidade propositiva em relação aos problemas e obstáculos à emancipação nas sociedades contemporâneas, em compreender e avaliar formas de pensamento e ação, na apresentação de potencialidades próprias das instituições democráticas.

\section{A política dos subaltern counterpublics de Fraser}

Para Nancy Fraser, a política da Teoria Crítica (Horkheimer, Habermas, Honneth) teria se afastado dos movimentos sociais. ${ }^{26}$ Em contrapartida, o

24 Werle \& Melo, "Reconhecimento e justiça na teoria crítica da sociedade em Axel Honneth", in: Nobre. Curso livre de Teoria Crítica. Papirus, 2008, p. 197. Grifo meu.

25 G. Saavedra \& E. Sobottka, "Introdução à teoria do reconhecimento de Axel Honneth", in: Civitas, Porto Alegre, 8, 1 (2008), p. 17-18.

${ }^{26}$ A bibliografia básica é: Nancy Fraser, "Que é crítico na teoria crítica? O argumento de Habermas e o gênero", in Benhabib \& Cornell. Feminismo como crítica da modernidade. Rosa dos Tempos, 1987. Ver também: Fraser, "Rethinking Recognition", in: New Left Review, 3 (2000), p. 107-20; Fraser. Justice interruptus. Critical reflections on the postsocialist condition. Routledge, 1997; e o debate com Honneth, in: Fraser \& Honneth. Umverteilung oder Anerkennung? Eine politischphilosophische Kontroverse. Suhrkamp, 2003. Ver também: F. Silva, "Iris Young, Nancy Fraser e Seyla Benhabib: uma disputa entre modelos críticos", in: Nobre. Curso livre de Teoria Crítica, Papirus, 2008, p. 199-226. 
debate americano busca religar o que estava separado desde Horkheimer: reintroduzir o "elo" com os movimentos sociais. ${ }^{27}$

O que Fraser critica aqui é a inexistência de um projeto emancipatório que pudesse reagregar adequadamente novas frentes de luta (desde Horkheimer e Habermas), mas também nos debates atuais dos representantes da Teoria Crítica em torno das "políticas de identidade", das "políticas culturais", do "reconhecimento das diferenças" (especialmente em Honneth e Young), ${ }^{28}$ em detrimento - ou substituição - à (antiga) preocupação com a "redistribuição", a "igualdade", as "políticas sociais" e "políticas de classe" (postura que é caracterizada em Fraser pela expressão "condição pós-socialista", cf. Justice interruptus. Critical reflections on the postsocialist condition. Routledge, 1997). Para Fraser, ao contrário, a política da Teoria Crítica deve indicar a resolução dos conflitos. Ela precisa discutir e resolver casos concretos. Algo que até agora a Teoria Crítica não conseguiu "dar uma solução". ${ }^{29}$

Mas, qual é o ponto de referência empírico que serve de análise da política de Fraser? A política vai virar consultoria de movimento social? Este é o "gancho" da crítica de Nancy Fraser ao conceito-chave da política de Habermas: está na crítica feminista ao entendimento elitista e burguês da dinâmica interna da esfera pública. Tendo como pano de fundo sua preocupação com a "redistribuição" e a "igualdade", Fraser acentua as disparidades sociais e a exclusão das mulheres da esfera pública política habermasiana. ${ }^{30}$

Para Fraser, a teoria da esfera pública de Habermas, como ponto de partida, é um recurso indispensável. Entretanto, requer uma interrogação e reconstrução crítica. ${ }^{31}$ Para a autora de Justice Interruptus, o modelo habermasiano de esfera pública formulado em Strukturwandel der Öffentlichkeit, interessa para a compreensão de uma política feminista.

27 Algo não tomado também por Honneth, apesar deste reconhecer e depois acabar se curvando ao debate americano (cf. o debate Honneth \& Fraser. Umverteilung oder Anerkennung? Suhrkamp, 2003). No entanto, Honneth não vai dizer como "resolver conflitos" (quem é o destinatário da teoria crítica de Honneth?). Este é questionamento de Fraser do deslocamento da "redistribuição" para "reconhecimento" operada por Honneth.

28 Especialmente Axel Honneth. Kampf um Anerkennung. Suhrkamp, 1992; e Iris Young. Justice and the politics of difference. Princeton Univ. Press, 1990.

29 Veja-se o que diz Fraser no artigo "Que é crítico na teoria crítica?", p. 38: "A meu ver, ninguém aperfeiçoou ainda a definição de Marx, de 1843, de Teoria Crítica como ‘o auto-aclaramento das lutas e desejos de uma época'. O que é tão atraente nessa definição é seu caráter francamente político".

30 Fraser, "Rethinking the public sphere: a contribution to the critique of the actually existing democracy", in: Calhoun. Habermas and the public sphere. MIT Press, 1992, p. 109-42.

31 Fraser, "Rethinking the public sphere", p. 109-11. 
Em outras palavras, a categoria de esfera pública é útil para descrever o significado político de novas formas de práxis que emergem com o movimento feminista nas décadas de 1970 e 1980. Atividades políticas que operam com estruturas não-institucionais e que têm gerado projetos coletivamente descentralizados, tais como grupos e publicações feministas. ${ }^{32}$ Esses fenômenos, se articulados com a esfera pública discursiva como categoria política central, adquirem um caráter emancipatório, embora a categoria de esfera pública, ou seu desenvolvimento histórico, sempre tenha funcionado como instrumento específico de repressão e distinção; ${ }^{33}$ o princípio formal burguês da igualdade de participação, que busca suspender ou eliminar a diferença de status, sempre foi problemático. Por isso, Fraser não concorda com a concepção (sociológica) da esfera pública habermasiana e, nesse sentido, invalida o modelo liberal burguês de comunicação e participação pública, que se assentaria sobre uma base social desigual, e que marginaliza mulheres e classes plebéias. ${ }^{34}$ Esse diagnóstico lhe permite fazer uma crítica da exclusão. Para Fraser, o que se faz necessário é eliminar as disparidades sociais e as diferenças de gênero.

A condição necessária para igualdade participativa é que as desigualdades sociais sejam eliminadas. Isso não significa necessariamente que todos devam ter exatamente a mesma renda, mas requer um tipo de igualdade que é inconsistente com relações de dominação geradas sistêmicamente [...] Democracia política requer substantiva igualdade social. ${ }^{35}$

Como contraproposta, Fraser sinaliza a necessidade do reconhecimento efetivo de certos públicos alternativos, subversivos, ou subaltern counterpublics, nos quais circulam discursos de oposição de alguma forma discriminados e excluídos da "esfera pública oficial". E, nesse sentido, recusa a idéia de que esses discursos alternativos e de oposição deixem se abarcar em "uma" esfera pública homogênea, mas sim em "várias" esferas públicas, autônomas, informais, que organizam e trazem à cena pública temas e contribuições politicamente relevantes. Uma sociedade cada vez mais pluralista, de enorme pluralização da sociedade civil, de fragmentação das estruturas de sociabilidade e solidariedade, na qual as aspirações emancipatórias vão sendo transferidas para outras (sub) bandeiras, enfrenta também o problema da "orientação comum" dessas

32 Fraser, "Rethinking the public sphere", p. 123. Ver também: Nancy Fraser, "Que é crítico na teoria crítica? O argumento de Habermas e o gênero", in: Benhabib \& Cornell. Feminismo como crítica da modernidade. Rosa dos Tempos, 1987.

33 Fraser, "Rethinking the public sphere", p. 115.

34 Fraser, "Rethinking the public sphere", p. 117-119.

35 Fraser, "Rethinking the public sphere", p. 121. 
esferas autônomas, com as dificuldades de se constituir "uma" esfera pública comum. ${ }^{36}$ Daí a introdução fraseriana da distinção entre weak publics e strong publics. ${ }^{37}$

\section{Referências}

BENHABIB, Seyla. Democracy and difference. Princeton Univ. Press, 1996.

. The claims of culture. Princeton Univ. Press, 2002.

BENHABIB, Seyla; CORNELL, Drucilla. Feminismo como crítica da modernidade. Rosa dos Tempos, 1987.

CALHOUN, Craig. Habermas and the public sphere. MIT Press, 1992.

CHAMBERS, Simone. "The politics of Critical Theory". In: RUSH, F. The Cambridge Companion to Critical Theory. 2004, p. 219-247.

DEWS, Peter. Habermas: a critical reader. Blackwell, 1999.

FRASER, Nancy. "Que é crítico na teoria crítica? O argumento de Habermas e o gênero". In: BENHABIB, S.; CORNELL, D. Feminismo como crítica da modernidade. Rosa dos Tempos, 1987.

. "Rethinking the public sphere: a contribution to the critique of the actually existing democracy". In: CALHOUN, C. Habermas and the public sphere. MIT Press, 1992, p. 109-142. 1997.

. Justice interruptus. Critical reflections on the postsocialist condition. Routledge,

. "Rethinking Recognition", New Left Review, 3 (2000), p. 107-120.

FRASER, Nancy; HONNETH, Axel. Umverteilung oder Anerkennung? Eine politischphilosophische Kontroverse. Suhrkamp, 2003.

FREUNDLIEB, Dieter. Critical Theory after Habermas: encounters and departures. Brill Verlag, 2004.

HABERMAS, Jürgen. Faktizität und Geltung. Frankfurt: Suhrkamp, 1992. 2v.

. "Drei normative Modelle der Demokratie". In: . Die Einbeziehung des Anderen. Suhrkamp, 2006, p. 277.

. "Political communication in media society". 2006 (manuscrito).

HAHN, Lewis. Perspectives on Habermas. Open Court, 2000.

HANKS, James K. Refiguring critical theory: Jürgen Habermas and the possibilities of political change. Univ. Press of America, 2002.

HONNETH, Axel. Kritik der Macht. Suhrkamp, 1985.

. Kampf um Anerkennung. Suhrkamp, 1992.

. "The other of justice: Habermas and the ethical challenge of postmodernism". In: WHITE, S. The Cambridge companion to Habermas. Cambridge Univ. Press, 1995, p. 289-323.

36 Fraser, "Rethinking the public sphere", p. 123ss.

37 Fraser, "Rethinking the public sphere", p. 132. 
HONNETH, Axel. "The social dynamics of disrespect: situating critical theory today". In: DEWS, P. Habermas: a critical reader. Blackwell, 1999, p. 320-337. . Leiden an Unbestimmtheit. Suhrkamp, 2001. . Verdinglichung. Eine anerkennungstheoretische Studie. Suhrkamp. 2005. . Pathologien der Vernunft. Geschichte und Gegenwart der Kritischen Theorie. Suhrkamp, 2007.

. Disrespect: the normative foudations of critical theory. Polity Press, 2007.

LUBENOW, Jorge A. "A categoria de esfera pública em Jürgen Habermas: para uma reconstrução da autocrítica", Cadernos de Ética e Filosofia Política (USP), 10, 1 (2007), p. 103-123.

LUBENOW, Jorge A.; NEVES, R. "Entre promessas e desenganos: lutas sociais, esfera pública e direito". In: NOBRE, M.; TERRA, R. Direito e democracia: um guia de leitura. Malheiros, 2007, p. 249-267.

MARSH, James L. "What's critical about critical theory?". In: HAHN, L. Perspectives on Habermas. Open Court, 2000.

NOBRE, Marcos. "Luta por reconhecimento: Axel Honneth e a Teoria Crítica". In: HONNETH, A. Luta por reconhecimento: a gramática moral dos conflitos sociais. Ed. 34, 2003, p. 07-19.

. A teoria crítica. Zahar, 2004.

. (Org). Curso livre de Teoria Crítica. Papirus, 2008.

NOBRE, Marcos; COELHO, Vera. Participação e deliberação. Editora 34, 2004.

NOBRE, Marcos; TERRA, Ricardo. Direito e democracia: um guia de leitura. Malheiros, 2007.

RUSH, Fred. The Cambridge Companion to Critical Theory. Cambridge Univ. Press, 2004.

SAAVEDRA, Giovani A.; SOBOTTKA, Emil A. "Introdução à teoria do reconhecimento de Axel Honneth", Civitas, Porto Alegre, 8, 1 (2008), p. 9-18.

SILVA, Felipe G. "Iris Young, Nancy Fraser e Seyla Benhabib: uma disputa entre modelos críticos". In: NOBRE, M. Curso livre de Teoria Crítica, Papirus, 2008, p. 199226.

SOUZA, Jessé. A modernidade seletiva. Brasília: Ed. UnB, 2000.

WERLE, Denílson. "Democracia deliberativa e os limites da razão pública”. In: NOBRE, M.; COELHO, V. Participação e deliberação. Editora 34, 2004, p. 148-49.

WERLE, Denílson; MELO, Rúrion S. "Reconhecimento e justiça na teoria crítica da sociedade em Axel Honneth". In: NOBRE, M. (Org.). Curso livre de Teoria Crítica. Papirus, 2008, p. 183-198.

WHITE, Stephen. The Cambridge companion to Habermas. Cambridge Univ. Press, 1995.

YOUNG, Iris M. Justice and the politics of difference. Princeton Univ. Press, 1990. . Inclusion and democracy. Oxford Univ. Press, 2000. 